\title{
Papers
}

\section{Healer shopping in Africa: new evidence from rural-urban qualitative study of Ghanaian diabetes experiences}

\author{
Ama de-Graft Aikins
}

\begin{abstract}
Objectives To provide counterevidence to existing literature on healer shopping in Africa through a systematic analysis of illness practices by Ghanaians with diabetes; to outline approaches towards improving patient centred health care and policy development regarding diabetes in Ghana.

Design Longitudinal qualitative study with individual interviews, group interviews, and ethnographies.

Settings Two urban towns (Accra, Tema) and two rural towns (Nkoranza and Kintampo) in Ghana.

Participants 26 urban people and 41 rural people with diabetes with diverse profiles (sex, age, education, socioeconomic status, diabetes status).

Results Six focus groups, 20 interviews, and three ethnographical studies were conducted to explore experiences and illness practices. Analysis identified four kinds of illness practice: biomedical management, spiritual action, cure seeking (passive and active), and medical inaction. Most participants privileged biomedicine over other health systems and emphasised biomedical management as ideal self care practice. However, the psychosocial impact of diabetes and the high cost of biomedical care drove cure seeking and medical inaction. Cure seeking constituted healer shopping between biomedicine, ethnomedicine, and faith healing; medical inaction constituted passive disengagement from medical management and active engagement with faith healing. Crucially, although spiritual causal theories of diabetes existed, they were secondary to dietary, lifestyle, and physiological theories and did not constitute the primary motivation for cure seeking. Cure seeking within unregulated ethnomedical systems and non-pharmacological faith healing systems exacerbated the complications of diabetes.

Conclusions To minimise inappropriate healer shopping and maximise committed biomedical and regulated ethnomedical management for Ghanaians with diabetes, the greatest challenges lie in providing affordable pharmaceutical drugs, standardised ethnomedical drugs, recommended foods, and psychosocial support. For health systems, the greatest challenges lie in correcting structural deficiencies that impinge on biomedical practices, regulating ethnomedical diabetes treatment, and foregrounding faith healer practices within diabetes policy discussions.
\end{abstract}

\section{Introduction}

Healer shopping, a term derived from doctor shopping, has been defined as "the use of a second healer without referral from the first for a single episode of illness." Studies suggest that healer shopping within ethnomedical systems is the primary and dominant response for chronically ill people in Africa. ${ }^{2-4}$ This practice is driven by widespread spiritual causal theories of chronic illness, the need for cures, and the endorsement of ethnomedical professionals-in particular traditional religious healers-as experts in treating and curing spiritually caused conditions. Because biomedicine cannot attend to the spiritual underpinnings of chronic conditions, people are unlikely to choose biomedicine in the first instance, may be non-compliant, or may abandon biomedicine. These culturally driven practices are deemed to present the greatest threat to self care and biomedical goals.

Counterevidence exists on general illness practices. Researchers note that healer shopping choices do not depend exclusively on (cultural and other) theories of illness causation, or commitment to particular health systems on the basis of distinct areas of medical expertise, but also, crucially, on the severity and timeframe of the illness and the cost, availability, and accessibility of pluralistic medical services. ${ }^{5-7}$ A systematic analysis of these economic, structural, and psychosocial dimensions for chronic illness practices is yet to be conducted. Given that most African health systems are economically constrained by the double burden of disease and possess few resources for chronic illness care, ${ }^{8}$ and ethnomedical and alternative healing systems constitute primary health care for most African populations, ${ }^{9}$ such an analysis can provide useful empirical information for the development of practical and cost effective interventions for chronic illness. The aim of this study was to critically examine illness practices and suggest approaches towards improving patient centred health care and policy development within the context of diabetes in Ghana.

Diabetes is a major cause of adult disability and death in Ghana. ${ }^{11}$ Recent studies and policy discussions strongly attribute the burden of diabetes to deficiencies in health systems, which include high medical costs, unavailability of drugs, and poorly staffed and financed diabetes services and poor patient practices, chiefly biomedical non-compliance and healer shopping for ethnomedical treatments. ${ }^{10-12}$ Researchers attribute poor patient practices to problematic cultural beliefs (such as spiritual causal theories) and poor knowledge of the clinical complexities of diabetes.

\section{Methods}

Most work on diabetes has been done in southern urban settings, although prevalence is documented in other parts of the country. ${ }^{10}{ }^{11}$ I recruited participants from two urban towns, Accra and Tema, and two rural farming towns, Kintampo and Nkoranza, located in the country's middle belt, to redress the 


\begin{tabular}{l}
\hline \multicolumn{3}{l}{ Table 1 Participant distribution and data collection method } \\
\begin{tabular}{lll} 
Method & Urban (Accra, Tema) & Rural (Nkoranza, Kintampo) \\
\hline Individual interviews & 11 (8 men, 3 women) & 12 (4 men, 8 women) \\
\hline Group interviews & 2 (7 men, 8 women) & 4 (15 men, 14 women) \\
\hline Ethnographies & 1 man (with 2 primary and & 2 women (with 3 primary and \\
& 3 secondary care givers) & 3 secondary care givers) \\
\hline
\end{tabular}
\end{tabular}

Table 2 Participant demographics: people with diabetes

\begin{tabular}{|c|c|c|c|}
\hline & \multirow[b]{2}{*}{ Total No } & \multicolumn{2}{|c|}{ Urban-rural distribution } \\
\hline & & Urban (n=26) & Rural ( $n=41$ ) \\
\hline \multicolumn{4}{|l|}{ Age (years) } \\
\hline $21-40$ & 9 & 2 men, 1 woman & 4 men, 2 women \\
\hline $41-60$ & 33 & 6 men, 6 women & 6 men, 15 women \\
\hline $61-80$ & 24 & 7 men, 4 women & 8 men, 5 women \\
\hline$>80$ & 1 & None & 1 man \\
\hline \multicolumn{4}{|l|}{ Education } \\
\hline None & 21 & 1 man & 6 men, 14 women \\
\hline Primary & 12 & 3 women & 4 men, 5 women \\
\hline Secondary & 20 & 5 men, 5 women & 7 men, 3 women \\
\hline University/postgraduate & 14 & 9 men, 3 women & 2 men \\
\hline \multicolumn{4}{|l|}{ Socioeconomic status } \\
\hline Unemployed & 5 & 1 woman & 4 women \\
\hline Retired & 17 & 6 men, 2 women & 7 men, 2 women \\
\hline Low income & 35 & 4 men, 3 women & 12 men, 16 women \\
\hline Middle income & 4 & 1 man, 2 women & None \\
\hline High income & 7 & 4 men, 3 women & None \\
\hline \multicolumn{4}{|l|}{ Diabetes status } \\
\hline Type 1 & 18 & 5 men, 3 women & 4 men, 6 women \\
\hline Type 2 & 49 & 10 men, 8 women & 15 men, 16 women \\
\hline \multicolumn{4}{|l|}{ Chronic illness status } \\
\hline $\begin{array}{l}\text { Hypertension, prostate } \\
\text { cancer, asthma }\end{array}$ & 20 & 8 men, 5 women & 4 men, 16 women \\
\hline
\end{tabular}

demographic imbalance. I recruited some participants formally from hospitals. At the Korle-Bu teaching hospital in Accra, I recruited participants from the diabetes clinic; in Nkoranza, participants were members of a self help group affiliated to the district hospital, St Theresa's. Because no organised social or medical support group existed in Kintampo, I compiled a contacts list, with official permission, from the Kintampo General Hospital's records of people who had sought treatment for diabetes in the preceding year. This facilitated door to door recruitment of participants in Kintampo town and neighbouring villages. I recruited other rural and urban participants opportunistically and through a snowball process across a variety of social, ethnomedical, and faith healing settings.

Data collection and analysis were part of a larger theory driven multi-method longitudinal study, reported elsewhere, that focused on people with diabetes, lay healthy people, and health professionals working within biomedical, ethnomedical, and faith healing systems. ${ }^{13}{ }^{14}$ The theoretical framework-social representations theory-emphasises that everyday social knowledge, interaction, and practice are shaped by "competing versions of reality." ${ }^{15} 16$ Criteria for sampling and analysis therefore underscored the diversity and complexity of illness experiences and practices; I paid systematic attention to sex, age, and educational and socioeconomic differences, as well as differences in diabetes status and illness trajectory.

\section{Data collection}

I used three methods to gather data: individual interviews, group interviews, and ethnographies (table 1). Individual interviews tap into individual biographies and thus "provide[s] the basic data for the development of an understanding of the relations between social actors and their situation.. ${ }^{17}$ Individual interviews were conducted with 20 participants to gather subjective accounts of illness experiences and practices.

Whereas the individual interview relies on the subjective account, the group interview examines the structure, process, and outcomes of social communication. This provides insight into "how knowledge, and more importantly, ideas, develop and operate within a given cultural context."18 Six focus groups were carried out with 44 rural and urban people to gather accounts and meanings of shared experience. Table 2 shows the demographics of the people who took part in individual or group interviews.

Both individual and group interviews are inadequate as tools to examine the social interactions and practices that shape subjective worlds. Ethnographies facilitate powerful analysis of these processes, as their object of study is locally produced "through the activities of particular people in particular settings." ${ }^{19}$ I did six month ethnographies with three people with diabetes and significant others in their life worlds (table 3). These constituted multiple interviews (at least three) with each primary interviewee, observation of participants, and reflexive field notes, during monthly home visits.

Initial interview guides were informed by key empirical and policy themes within local and regional discussions on diabetes, as well as health psychology perspectives on chronic illness. I further refined the guides after interviews with 11 Ghanaian healthcare and policy experts. Guides for rural interviews, conducted in the local Akan language, Bono; two urban interviews conducted in the Akan languages Fanti and Twi; and one urban focus group discussion, conducted partially in Ga language, were further refined to reflect culturally appropriate meanings, after consultation with local field and translation experts. I am British, of Ghanaian (Akan) parentage. I can understand, read, and speak Fante and Twi fairly well but have less intricate knowledge of $\mathrm{Ga}$ and Bono. I did all urban English, Twi, and Fanti interviews and ethnography myself. A local field assistant did the urban Ga focus group, and three field assistants did rural individual and group interviews and ethnography interviews with myself in attendance as facilitator and note taker. Group discussions lasted from an hour to two hours. One rural group discussion lasted six hours over a three day period. Individual interviews lasted between 40 and 90 minutes. Permission was sought and granted to record all interviews and discus-

\section{Table 3 Ethnography participant demographics}

\begin{tabular}{|c|c|}
\hline Life world & Participant profile \\
\hline \multirow[t]{6}{*}{ Urban } & John (EL), 56; diabetes duration 15 years; retired serviceman \\
\hline & Diane (EL), 60; John's wife; primary carer; retired bank clerk \\
\hline & Hannah (EL), 30; John's daughter; carer; teacher/university student \\
\hline & $\begin{array}{l}\text { Patricia }^{*} \text { (EL), 50s; Diane’s sister; employment status unspecified } \\
\end{array}$ \\
\hline & Charles* (EL); John's son; carer; apprentice "technician" \\
\hline & Patrick (EL); John's associate; lay preacher \\
\hline \multirow[t]{3}{*}{ Rural } & $\begin{array}{l}\text { Maame-Efua, 70; diabetes duration eight years; retired trader/bar } \\
\text { owner }\end{array}$ \\
\hline & $\begin{array}{l}\text { Alice, 32; Maame-Efua's daughter/primary carer; hairdresser (lives } \\
\text { with diabetes) }\end{array}$ \\
\hline & Grace, late 30s; Maame-Efua's daughter/occasional carer; teacher \\
\hline \multirow[t]{5}{*}{ Rural } & Ruth, 50; diabetes duration six years; food hawker \\
\hline & Adjoa, 29; Ruth's daughter; trader \\
\hline & Cynthia, 40; Ruth's niece; teacher \\
\hline & George (EL); Ruth's family friend; self help group secretary \\
\hline & Jane*; Ruth's neighbour; unemployed; self help group member \\
\hline
\end{tabular}
All names are pseudonyms.

$\mathrm{EL}=$ interviews conducted in English.

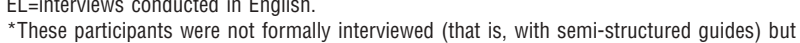
were informal discussants, members of the household or community, who joined in group discussions during home visits or informal conversations before, during, or after home visits. 
sions. All participants were remunerated for participation. English interviews were transcribed verbatim. Bono, Twi, Fanti, and Ga transcripts were translated and transcribed jointly by bilingual research assistants and myself.

\section{Analysis}

I used the qualitative analysis package Atlas-ti to code all transcripts. Coding aimed to capture the range of views on the empirical categories of health, chronic illness and diabetes knowledge, knowledge and use of pluralistic medical systems, diabetes experiences, and illness practices (box 1). Informed by social representations theory, I paid attention to consensus, conflict, and absences across group and individual narratives.

With individual interview transcripts, I contextualised consensus, conflict, and absence within a singular unfolding narrative. I used a two stage process for focus group transcripts: firstly, I identified broad areas of group consensus, conflict, and absences; secondly, I followed through individual narratives systematically, where appropriate, to examine the progression and nature of interpersonal consensus, conflict, or changes in views within the group context. For each ethnography, I cross referenced individual transcripts, observation material, and field notes to identify consensus and divergences within a family unit. This systematic process facilitated the identification of converging and diverging discourses, motivations, relations, and practices between and within groups (such as urban and rural groups, people with type $1 v$ type 2 diabetes).

I used an intra-coder reliability test-a process that measures the consistency of a single coder coding the same material twice with a time interval-for the local language transcripts, given their complex multi-ethnic and language dimensions..$^{20} \mathrm{~A}$ second coder subjected a selection of English transcripts to an inter-coder reliability test.

\section{Results}

Analysis identified four kinds of illness practice adopted by participants: biomedical management, spiritual action, cure seeking, and medical inaction. Results are presented under these core themes.

\section{Biomedical management}

Most participants sought biomedical care in the first instance and endorsed biomedical management as ideal self care practice. This stemmed from two factors. Firstly, biomedical, ethnomedical, and faith healing systems were subjected to public critique in terms of technical or practical knowledge of health problems, technological expertise, accessibility, and ethics; all three had strengths and weaknesses across these criteria, depending on the health problem. Chronic illnesses belonged to the category of complex contemporary illnesses; here, doctors were endorsed as diagnostic and pharmacological experts, and biomedical knowl-

Box 1: Key areas explored in individual interviews, group interviews, and ethnographies

- Biographical and demographic data

- Knowledge of general health and illness categories, chronic illness, and diabetes

- Knowledge and use of pluralistic medical systems

- Diabetes experiences: impact of diabetes on everyday experiences and social and medical relationships

- Illness practices: the influence of knowledge, experience,

relationships, and material resources on illness practices edge systems and practices were privileged over ethnomedical and faith healing systems, both described as diagnostically and pharmacologically inept and lacking professional ethics.

Secondly, biomedical explanations of and solutions to causes of diabetes were publicly legitimised. Diabetes was attributed to an array of interchangeable causes: high sugar diets, heredity, physiological imbalance, toxic foods, and spiritual disruption. High sugar diets and physiological imbalance were deemed primary causes, for which biomedicine offered the most successful solutions. Although the level of sophistication of biomedical explanations of diabetes increased with education, both uneducated and educated participants held sufficient biomedical knowledge on diabetes to prioritise drug and dietary management over alternative medical and self care practices.

Some participants remained committed to biomedical management. This group had three distinct or interlinked experiences: people who had lived with diabetes in the long term; people who had experienced few or no life disruptions from diabetes; and people who lived with other serious conditions, such as hypertension and prostate cancer. Practical daily routines were geared towards controlling symptoms through drug and dietary management and routine lifestyle change (drinking less, taking up exercise).

However, for most participants, biomedical management was undermined by two key factors. Firstly, daily drug and dietary management routines imposed a considerable psychosocial burden on all participants. Secondly, the high cost of biomedical drugs and recommended foods undermined the commitment of low income and financially destitute groups to long term engagement in biomedical care. For example, rural participants paid $60000-90000$ cedi (£6-9; \$11-16.5; €8.8-13.2 at the time of the study) for a monthly supply of insulin. This constituted $60 \%$ of the monthly income of those on a minimum daily wage of 5000 cedi $(£ 0.50)$.

\section{Spiritual action}

There were two dimensions to spiritual action. Within rural communities, diabetes was partially attributed to two spiritual causes: witchcraft (malevolent action caused by "witches"people possessing mystical powers used to harmful ends) and sorcery (malevolent action caused by ordinary people through knowledge and use of spells or rituals). For some, these constituted primary theories and demanded traditional religious intervention. For instance, five participants sought traditional religious healing initially because the suddenness and mysteriousness of their symptoms were attributed to witchcraft. Consultation was short lived, and all turned to biomedical intervention as their physical health deteriorated. For most, spiritual causal theories were secondary to biological, lifestyle, and heredity theories and were drawn on only if a discrepancy existed between their pre-diagnosis knowledge of diabetes and their subjective experiences. Crucially, this group made a distinction between legitimate and illegitimate spiritual action: the first occurred within the Christian sphere and the second in the traditional religious sphere. This distinction resonated with broader rural and urban discussions of general illness practices.

The second kind of spiritual action, Christian prayer, was more widespread and had a consensual motivational basis. Most rural and urban participants were practising Christians, who stressed that as everyday experiences and practices required spiritual mediation-prayer and Christian communion-diabetes treatment required spiritual mediation. Spiritual intervention offered by faith healers was rejected because of empirical failures of faith healing. People who had sought faith healing in the past 
drew attention to faith healers' inability to diagnose and their emphasis on fasting as a primary healing technique. Several participants attributed past complications to ineffectual faith healing practices.

\section{Cure seeking-passive and active}

Although participants understood and stressed that diabetes was incurable, many hoped for a cure. Discourses on "hope for a cure" centred predominantly on a collective need for relief from the physical and psychological burden of drug and dietary management and was synonymous with hope for future biomedical breakthroughs. This need shaped passive cure seeking, which constituted intermittent healer shopping, particularly during acute illness phases (see box 2). Socioeconomic status and geographical location shaped distinct healer shopping choices. Wealthy urban people were more likely to doctor shop. When they healer shopped for ethnomedical treatment, a persistent preference was for scientifically approved ethnomedical drugs. Low income urban and rural groups, with fewer material resources and restricted access to biomedical services and regulated ethnomedical services, healer shopped within mainly unregulated ethnomedical services; some augmented ethnomedical care with biomedical dietary advice. Most participants reported negative experiences from unregulated ethnomedical treatments. Problems included unspecified dosages, unclear information about drug action, and side effects of drugs. By contrast, wealthy urban groups endorsed the pharmacological benefits of scientifically approved ethnomedical drugs. Although participants remained highly critical of unregulated ethnomedicine, few had recourse to desired alternatives.

A minority of participants believed that diabetes could be cured; this group constituted mainly rural, and low income, people recently diagnosed with diabetes or experiencing acute physical disruption. Their belief was fuelled by unwavering faith in God's ability to heal all health problems. This group engaged in active cure seeking, which constituted persistent and committed healer shopping between ethnomedical and faith healing systems. Some combined ethnomedical drug treatment with biomedical dietary management.

\section{Medical inaction}

Medical inaction constituted passive withdrawal from drug and dietary management. This, according to the narratives of low income groups, was underpinned by chronic suffering characterised by severe financial difficulties, escalating complications, and a lack of family and social support. During fieldwork,

\section{Box 2: An urban case study}

John had lived with diabetes for 15 years and had a longer history of hypertension. John and his family attributed his diabetes to a mix of dietary imbalance, poor lifestyle practices (smoking and drinking), and heredity. Three weeks before the ethnography, he had had a leg amputated. He could not return to his casual post-retirement job as a security guard as a result, and his loss of income had a considerable impact on his family's finances. The family's struggle with a diminished budget was compounded by the ongoing need for expensive insulin treatment and dietary management.

His family was committed to his care, despite the financial constraints. His wife Diane provided round the clock care, and his older daughter Hannah and son Charles took extended time off work to provide secondary care. A daughter who lived abroad sent regular donations to supplement her parents' pension. A young priest and family friend, Patrick, came by regularly to offer John and his family spiritual and moral support.

For much of the duration of the fieldwork, John oscillated between depression and anger at his disability, and he often withdrew from making decisions about his medical care and self care. Diane and Hannah, therefore, took active daily control of his diabetes treatment. Their daily strategies remained constant throughout the fieldwork and involved administering drugs, preparing foods recommended by the doctor, weekly measurement of John's blood sugar level (using a tester kit provided by the daughter living abroad), and prayer. When the family could afford it, Diane paid for physiotherapy.

At the start of the ethnography, Diane and Hannah discussed their decision to seek ethnomedical treatment for John. They expressed frustration at the slow healing of his amputated leg and the deteriorating state of the remaining leg and fear of complications and potential amputation in the future. They needed drugs that could heal the amputated limb faster, improve the condition of the remaining leg, and prevent further complications. They chose a herbalist whose medicines, according to Hannah, had cured her aunt Patricia's husband of diabetes. All other practical routines-biomedical dietary management, prayer, and physiotherapy-would remain unchanged. They expressed great confidence in the efficacy of their chosen ethnomedical treatment and noted that in the unlikely event that this treatment failed, they would "switch back to" insulin treatment.

By the second month of fieldwork, John had received ethnomedical drugs from the herbalist. This occurred without face to face consultation. Patricia had delivered the drugs. Insulin treatment was abandoned for exclusive use of this new treatment. In addition, the family decided to consult faith healers to strengthen the efficacy of the herbal treatment. They chose a prayer camp, based in a neighbouring town, which advertised its services on radio and television and whose "miracles" had received some endorsement within their community.

AdGA: "What are your reasons for using these types of treatment?"

Hannah: "So that my dad gets healed fast."

AdGA: "Tell me some more."

Hannah: "OK, we've tried the Western type of medicine for a long time ... but it's not getting better as we would want it; we want see the other aspect the traditional and the religious one, see whether it will help him to be fine, even if he will be able to stand on the other foot or use the crutches since some people have been able through the religious line have been able to cure some people who are lame and who are not able to walk."

Problems arose with the ethnomedical treatment. The drugs were ineffective. Furthermore, the herbalist had taken time off work to attend to family responsibilities, and John's family had no access for advice on treatment regimens. According to Diane, the first faith healing consultation had been positive: the principle pastor assured the family of his ability to cure John of diabetes and advised regular visits to facilitate the curative process. However, the cost of travel was high, and after two further visits to the prayer camp this mode of treatment was abandoned.

By the fourth month of fieldwork, the family had returned to exclusive use of biomedical treatment and, for adjunctive spiritual support, private prayer and regular visits from Patrick. This continued for the remainder of the fieldwork. Friends and family recommended and brought a variety of herbal remedies for John's diabetes, although discussions with John and his family suggest that these remedies were not used. 
five rural and urban participants were medically inactive. They made frequent references to depression and suicidal thoughts. They all emphasised that death was a desirable alternative to chronic suffering. Participants in Nkoranza received psychosocial support from their self help group, but this did not address the critical financial support needed for diabetes management.

Although this group had passively disengaged from medical care, they were spiritually active. They engaged in constant prayer, simultaneously seeking death as an end to chronic suffering and a miracle (such as a change in socioeconomic circumstances, a benefactor) to have their health restored. Additionally, and despite awareness of the shortcomings of faith healers, this group relied on faith healing (see box 3).

\section{Discussion}

Healer shopping for ethnomedical treatment is viewed as a dominant practice among people with chronic illnesses in Africa and has been attributed to widespread spiritual causal theories of chronic illness, the need for cures, and the endorsement of ethnomedical professionals as spiritual experts. Similar assumptions underpin diabetes research in Ghana: poor practices by patients are attributed to spiritual causal theories and poor knowledge of the clinical complexities of diabetes. This study identified four kinds of illness practice adopted by Ghanaians with diabetes, which offered greater insight into the sociocultural, psychosocial, and structural dimensions of medical care and self care. The discussion will focus firstly on how these findings challenge dominant claims made in current regional and local literature and will then move on to implications for research and policy on diabetes in Ghana.

\section{Healer shopping: three findings on choices and motivation}

Firstly, healer shopping for ethnomedical treatment was not the primary choice for most participants. Biomedical management was a preferred persistent choice. However, the high cost of biomedical care, coupled with the psychosocial burden of diabetes, set most people on a passive cure seeking course; a minority either actively sought cures or became medically inactive. Crucially, as the processes of cure seeking and medical inaction showed, healer shopping did not occur only within ethnomedical systems but across biomedical, ethnomedical, and faith healing systems. Different choices depended on people's socioeconomic status and access to these pluralistic services, as well as on whether participants hoped for a biomedical breakthrough or believed in a (Christian) spiritual cure for diabetes.

Secondly, the findings challenged the claim that healer shopping was underpinned by problematic spiritual causal beliefs, the

\section{Box 3: A rural case study}

Ruth had lived with diabetes for six years. Ruth's family attributed her diabetes to a mix of diet and lifestyle factors; although Ruth concurred with her family, she also speculated that she may have got diabetes through her brother's sorcery. She lived with severely uncontrolled diabetes and chronic physical impairments: loss of appetite, severe weight loss, joint pains, and body sores. This had a pervasive impact on her life. She was unable to carry out the simplest everyday chores and had had to abandon her previous job as a food hawker. As a result of her severe weight loss, she was labelled as having AIDS, ostracised by her community, and abandoned by her partner.

In the early years, she had financial support from her extended (paternal) family for biomedical treatment; but she was on insulin, which was expensive, and gradually financial support had been withdrawn. Three care givers were identified: an older daughter, Adjoa, widowed with three children, all of whom lived with Ruth; a son who lived locally, visited rarely, but made her annual community health insurance contributions; and a niece, Cynthia, a teacher, who helped financially when she could. Other forms of financial and social support came from sympathetic hospital staff and self help group members.

During fieldwork, Ruth had discontinued biomedical treatment because of financial constraints. She was admitted to hospital once during the fieldwork, from complications of uncontrolled diabetes. Hospital care was covered by her insurance. She had no resources to buy recommended foods and usually ate when she received donations from friends or when her daughter could afford to make family meals.

"Unless I go out for somebody to help me with about 1000 cedi, I go about without food. Since morning, I must confess I have not eaten anything. I have not eaten. I only bought one egg worth 500 cedi. That is the only thing I have had today." (Ruth)

"Well, I actually don't have enough money, so what I do for her is that, after selling my wares, I then go to the market to buy foodstuff and come home to cook some meal for all of us to eat. This is what I am able to do. If I have, I give her. If I don't have too, I make her aware that I don't have it." (Adjoa)

However, Ruth adopted three regular strategies to alleviate some of the disruptions caused by diabetes. She took herbal tonics to regain physical strength. This activity was dependent on financial donations from friends and family.

"When someone gives me 500 cedi, I will buy Aberewa Bebo Ball [literal translation: "old ladies will play (foot)ball"-a popular brand of herbal re-energising tonic] and will find some food to eat." (Ruth)

Although Ruth had experienced severe complications in the past from ethnomedical treatments, she often took herbal medicines, recommended or brought to her by friends as possible diabetes cures. This practice, according to both Ruth and her family members, was underpinned by her need to reduce the physical disruption of diabetes and her inability to afford biomedical care. These herbal medicines exacerbated her symptoms.

"About two weeks ago, a certain woman came to tell me I should chew these flowers which are red in colour. I chewed it and I had diarrhoea. I have since stopped chewing the flowers." (Ruth)

Finally, Ruth prayed and attended church regularly for spiritual support. She often stayed for entire days or overnight at prayer camp. She also attended self help group meetings regularly for social support. Ruth expressed constant despair at the severity of the impact of diabetes on her life and at her abandonment by her family. She often cried during interviews. She made recurrent references to death as an end to her chronic suffering, to her family and during interviews. Even as she was repeatedly drawn to suicide, she acknowledged her inability to act on this need, because her Christian faith abhorred suicide as a response to life's misfortunes.

"She is still in fear because since she got the disease, she has the feeling that she would die at any time. At times when she comes to me, she asks me, when is death coming for her? So, with these sayings, you realise that she is in fear." (Cynthia)

Ruth: "Recently, I even thought of committing suicide by poisoning myself."

DY: "Is that true?"

Ruth: "Yes. I have said that. And I say it each day. But I remind myself later on that it is the Lord who brought me into this world. And if I make my mind up about poisoning myself there would be a punishment for me one day. But I think of it very much." 
endorsement of traditional religious healers as spiritual experts, and the need for a cure. The motivations underpinning healer shopping drew on but transcended culture; the need for affordable and effective pharmacological treatment and relief from the physical and psychosocial burden of diabetes shaped medical care and self care. Spiritual causal theories held cultural legitimacy within the Ghanaian public sphere, but their structure and functions were complex. Two spiritual causal theories of diabetes-witchcraft and sorcery-emerged as primary or secondary theories for a minority of rural participants. As primary theories, witchcraft and sorcery took precedence over biological and lifestyle theories. As secondary theories, they were subordinate to alternative theories but assumed importance when the onset of diabetes seemed to have no biological or lifestyle basis. More importantly, spiritual causal theories did not shape illness practices as predictably as is reported in the literature. People who accessed traditional religious healing abandoned this for biomedical treatment as their physical health deteriorated. Others attributed their diabetes to spiritual causes but did not seek spiritual treatment. Evangelical Christianity has assumed increasing relevance as a mediator of solutions to everyday problems, including those of health and disease, in Ghana. ${ }^{21}$ Within this context, Christian faith healers wield legitimate and greater therapeutic power over traditional religious healers. Most participants distinguished between legitimate spiritual action, occurring within the Christian sphere, and illegitimate spiritual action within the traditional religious sphere; they were more likely-in the event of extreme physical and economic disruption-to seek faith healing rather than traditional religious healing.

Finally, biomedical knowledge and technical expertise on diabetes were privileged over ethnomedical and faith healing versions. Thus most educated and uneducated groups sought and held sufficient biomedical knowledge to understand that diabetes was incurable and to commit to biomedical management. For most people, hope for a cure was synonymous with hope for biomedical breakthroughs in diabetes treatment and distinct from minority belief in a cure that was subsumed within an all-encompassing faith in the healing power of a Christian God.

\section{Challenges for diabetes care in Ghana}

These findings may not be generalisable to other regional and ethnic contexts. For example, religious and policy responses might be different in northern Ghana, which is predominantly Muslim and served by a better equipped voluntary biomedical sector. However, the theory driven, multi-site, multi-experiential qualitative approach adopted has uncovered clear patterns of illness practice across key demographic arenas such as geographical location, socioeconomic status, diabetes status, and support systems; these can instruct new developments in diabetes policy and service delivery. For instance, wealthy urban people tend to doctor shop or healer shop for regulated ethnomedical services (highly concentrated in the urban south); they might find restricted diets oppressive, but they can afford these recommended alternatives. The health of this group is least compromised. For low income and rural people, and especially those on expensive insulin treatments, the consequences of living with diabetes are more severe; this group has least access to biomedical and regulated ethnomedical services, they cannot afford recommended foods, and they are likely to gravitate towards faith healers as a spiritual response to chronic suffering.

Challenges for health care and policy development lie in providing affordable drugs and food, prioritising psychosocial

\section{What is already known on this topic}

Healer shopping is the primary and dominant practice for Africans with chronic illness and is a function of culturally mediated spiritual beliefs and the need for cures

People abandon biologically centred biomedicine and gravitate towards ethnomedical systems because ethnomedicine is deemed to provide cures for spiritually caused conditions

Problematic ethnomedical treatment methods undermine self care and biomedical goals

\section{What this study adds}

Ethnomedical healer shopping within the Ghanaian diabetes context is a secondary practice, coexisting with biomedical management, spiritual action, and medical inaction

Spiritual causal theories exist but are secondary to biological and lifestyle theories; ethnomedicine is consulted for cheaper pharmacological, rather than spiritual, treatment

Healthcare goals are undermined by high cost of prescribed drugs and recommended foods, poor psychosocial support, and unregulated ethnomedical and faith healer treatments

support, and regulating faith healing practices. Policy discussions suggest that the provision of affordable or subsidised pharmaceutical drugs is unlikely to occur in the short term. ${ }^{11}$ Two partial solutions exist, however. A recently implemented national health insurance scheme provides cover for chronic conditions and may alleviate the financial burden for people who can afford premium payments. The second solution lies in the expanded use of scientifically approved ethnomedical drugs, which have proved effective for urban people on oral treatment. The clinical and policy climate is conducive for such a development; ongoing toxicological tests and clinical trials indicate that effective herbal medicines for diabetes exist, and research suggests that ethnomedical practitioners are willing to submit their drugs to trials if costs are covered and that doctors are willing to refer patients to regulated ethnomedical services. ${ }^{22}{ }^{23}$ This development may serve simultaneously as a regulatory exercise aimed at making ethnomedical diabetes care more transparent and the implementation of a referral system more sustainable.

The high cost of recommended foods is neglected in the local literature but deserves empirical work that engages with the agricultural and food export sectors. The lack of social and psychological services and a welfare system in countries such as Ghana places the burden of psychosocial and economic support on families. Low income families are unlikely to provide consistent, long term support to their diabetic relatives. ${ }^{24}$ Self help groups are becoming important providers of psychosocial support in Africa and other low income regions. ${ }^{25}{ }^{26}$ In Nkoranza, the diabetes self help group provided valuable support, especially for people abandoned by their families and community. Lessons can be drawn from this group for the other study sites. Finally, the role of faith healers as healthcare providers for people with diabetes deserves research and policy attention. Future research will have to examine the feasibility of 
developing educational and regulatory interventions that aim, simultaneously, to enhance their psychosocial and spiritual role and minimise damaging aspects of their healing repertoires.

I thank the research participants for sharing their time, thoughts, and experiences; the research contributors for invaluable fieldwork assistance; and Gerry Mshana, Liam Smeeth, Josip Car, Tim Stokes, Julie Morris, and John Fletcher for important comments made on an earlier version of this paper.

Contributors: AdGA did all urban English, Twi, and Fanti interviews and focus groups and coded all transcripts. Research contributors included Danso Yeboah, Judith Parry, and Mr Osei, who did rural Bono interviews and focus groups; Adote Anum, who did the urban Ga focus group; Love Debrah, Sammy Boafo, Regina Insaidoo, and Evelyn Tieku, who assisted in translating and transcribing transcripts. Anna Tetevie coded selected English individual and group interview transcripts.

Funding: Occasional student maintenance grants from the London School of Economics Financial Office.

Competing interests: None declared.

Ethical approval: Ghana Medical School ethics committee

1 Kroeger A. Anthropological and socio-medical health care research in developing countries. Soc Sci Med 1983;17:147-61.

2 Green EC. Sexually transmitted disease, ethnomedicine and health policy in Africa. Soc Sci Med 1992;35:121-30.

3 Kirby JP The Islamic dialogue with African traditional religion: divination and healthcare. Soc Sci Med 1993;36:237-47.

4 Nkwi PN. Perceptions and treatment of diarrhoeal diseases in Cameroon. J Diarrhoeal Dis Res 1994;12:35-41.

5 Rekdal OB. Cross-cultural healing in east African ethnography. Med Anthropol $Q$ 1999;13:458-82

6 Ryan GW. What do sequential behavioural patterns suggest about the medical decision-making process? Modeling home case management of acute illness in a rura Cameroonian village. Soc Sci Med 1998;46:209-25.

7 Nyamwaya D. A case study of the interaction between indigenous and Western medicine among the Pokot of Kenya. Soc Sci Med 1987;25:1277-87.

8 Unwin N, Setel P, Rashid S, Mugusi F, Mbanya J, Kitange H, et al. Noncommunicable diseases in sub-Saharan Africa: where do they feature in the health research agenda? Bull World Health Org 2001:79:947-53.

9 DeJong J. Traditional medicine in Sub-Saharan Africa: its importance and potential policy options. Washington, DC: World Bank, 1991.

10 Monitoring and Evaluation Team. Formative and baseline research on diabetes mellitus in Ghana. Accra: Ghana Diabetes Care and Disease Management Project, 1998.
11 Amoah AGB, Owusu KO, Adjei S. Diabetes in Ghana: a community prevalence study in Greater Accra. Diabetes Res Clin Pract 2002:56:197-205.

12 Ofei F, Forson A, Appia-Kusi J. Self-care behaviour amongst Ghanaian diabetics. Unpublished conference paper available from Dr Francis Ofei, University of Ghana Medical School, PO Box 4236, Accra, Ghana, 1996.

13 De-Graft Aikins A. Living with diabetes in rural and urban Ghana: a critical social psychological examination of illness action and scope for intervention. J Health Psychol 2003;8:557-72.

14 De-Graft Aikins A. Social representations of diabetes in Ghana: reconstructing self, society and culture. Unpublished PhD thesis. London School of Economics and Political Science, 2004.

15 Rose D, Efraim D, Gervais M, Joffe H, Jovchelovitch S, Morant N. Questioning consensus in social representations theory. Papers on Social Representations 1995;4(2):1-155.

16 Moscovici S, Duveen G. Social representations: explorations in social psychology. New York: New York University Press, 2000.

17 Gaskell G. Individual and group interviewing. In: Bauer M, Gaskell G, eds. Qualitative researching with text, image and sound: a practical handbook for social research. London: Sage, 2000:39.

18 Kitzinger J. Qualitative research: introducing focus groups. BMJ 1995;311:299-302, 310 .

9 Silverman D. Interpreting qualitative data: methods for analysing talk, text and interaction. London: Sage, 2001:70.

20 Krippendorff K. Content analysis. Beverly Hills: Sage Publications, 1980.

21 Bediako K. Africa and Christianity on the threshold of the third millennium. African Affairs $2000,99: 303-23$.

22 Government of Ghana (Ministry of Health). The health of the nation: analysis of health sector programme of work: 1997-2001. Accra: Ministry of Health, 2001.

23 De-Graft Aikins A. Exploring biomedical and ethnomedical representations of diabetes in Ghana and the scope for cross-professional collaboration: a social psychological approach to health policy. Social Science Information 2002;41:603-30.

24 De-Graft Aikins. Strengthening quality and continuity of diabetes care in rural Ghana: a critical social psychological approach.J Health Psychol 2004;9:295-309.

25 Valente TW, Watkins SC, Jato MN, van der Straten A, Tsitol LP. Social network associations with contraceptive use among Cameroonian women in voluntary associations. Soc Sci Med 1997;45:677-87.

26 Krause M. The transformation of social representations of chronic disease in a self-help group.J Health Psychol 2003;8:599-615.

(Accepted 31 August 2005)

bmj.com 2005;331:737

Department of Social and Developmental Psychology, Faculty of Social and Political Sciences, University of Cambridge, Cambridge CB2 3RQ

Ama de-Graft Aikins ESRC postdoctoral fellow

ada21@cam.ac.uk 